Journal of Engineering and Applied Sciences 14 (21): 7988-7995, 2019

ISSN: 1816-949X

(C) Medwell Journals, 2019

\title{
Android Based Low Cost Harmonic Analyzer
}

\author{
${ }^{1}$ Mat Syai' in, ${ }^{1}$ M.S.A. Sidik, ${ }^{2}$ N.H. Rohiem, ${ }^{2}$ M.F. Adiatmoko, ${ }^{2}$ Adi Soeprijanto and ${ }^{3}$ A.M. Hatta \\ ${ }^{1}$ Study Program of Automation Engineering, \\ Shipbuilding Institute of Polytechnic Surabaya (SHIPS/PPNS), \\ J1. Teknik Kimia, Kampus ITS Sukolilo, 60111 Surabaya, Indonesia \\ ${ }^{2}$ Department of Electrical Engineering, \\ Institute Teknologi Sepuluh Nopember (ITS), Surabaya, Indonesia \\ ${ }^{3}$ Department of Engineering Physics, \\ Institute Teknologi Sepuluh Nopember (ITS), Surabaya, Indonesia \\ matt.syaiin@ppns.ac.id
}

\begin{abstract}
This study proposes a prototype of harmonic analyzer that can be synchronized with Android. The prototype is used to measure and monitor harmonics in the power systems as well as micro grid system. The prototype of Android based Low Cost Harmonic Analyzer (ALCHA) is constructed by using current sensor, microprocessor, data base and Android Software. The advantage of ALCHA is very cheap comparing to commonly harmonic analyzer in the market. ALCHA utilizes available components on the market with affordable price and also, utilizes open source software. In this study, the observation is focus on harmonic 3rd, 5th, 7th and 9th and Total Harmonic Distortion (THD) that referring to IEEE 519 standard. Based on experiment results can be proof that ALCHA has capability for detecting harmonics that occur both in the power system and in the micro grid system. Standard deviation of ALCHA compared to laboratory scale harmonic analyzer is around $1.4 \%$.
\end{abstract}

Key words: Power systems, micro grid systems, harmonics, Total Harmonic Distortion (THD), Discrete Fourier Transformation (DFT) Android, ALCHA

\section{INTRODUCTION}

The development of information technology has opened the opportunity to apply the concept of science either based on numerical (Lian and Syaiin, 2014; Syaiin et al., 2012, 2013a-c) and artificial intelligent based (Syai' 'in and Soeprijanto, 2010; Syaiin and Soeprijanto, 2010; Syai'in et al., 2012, 2014, Adhitya et al., 2016; Putra et al., 2016; Rinanto et al., 2016) for solving engineering problems. At present, electricity sources are beginning to shift from fuel-based electricity sources to renewable energy-based electricity sources, the use of renewable energy-based electricity sources cannot be separated from the existence of converters. Using renewable energy-based electricity sources as power plant there is a lot of conversion of power from $\mathrm{DC}$ to $\mathrm{AC}$ and vice versa.

In general, the development of converter technology is intended to improve efficiency of it (Duckett, 1962; Cottinet et al., 2011; Cho et al., 2014; Mohebbi et al.,
2015; Shi et al., 2017). The power converter, Lian and Syaiin (2014) is widely known as a source of harmonics and many researcher developed technology to reduce the harmonics (Zhang et al., 2008; Jaipradidtham and Inban, 2009; Agarwal and Singh, 2014; Isozaki et al., 2016). Although, many researchers are trying to do research to reduce harmonics but until now the tool to monitor harmonics is still expensive. As an example of a harmonic analyzer used on (Goh et al., 2017).

Due to the high cost of harmonic analyzer in the case of harmonics that occur in the systems are tending to be ignored by people. It may result in damage for electronic appliance that utilizing the electricity as a source. On the other hand, the development of smartphones is also increasing both in terms of data processing speed and data storage capacity. This has influenced the behavior of people who want all activities to be carried out using a smartphone including monitoring systems.

In this study, we will propose a method to construct Android Low Cost Harmonic Analyzer (ALCHA) which utilizes sensors and microprocessors that commonly

Corresponding Author: Mat Syai'in, Study Program of Automation Engineering,

Shipbuilding Institute of Polytechnic Surabaya (SHIPS/PPNS), Jl. Teknik Kimia, Kampus ITS Sukolilo, 60111 Surabaya, Indonesia, matt.syaiin@ppns.ac.id 
available in the market with affordable price. The general process of constructing ALCHA is measuring current by using current sensor. The data from the sensor processes by microprocessor to calculate the harmonic distortion, then the data send to firebase and display to Android systems. The main process in microprocessor is conversion time domain to frequency domain by using Discrete Fourier Transformation (DFT) (Hostetter, 1980). In this study, prototype of ALCHA is focusing on harmonics the 3rd, 5th, 7th and 9th that occurs either in the power systems or micro grid systems with referring to IEEE 519 standard (Chang et al., 2014).

\section{MATERIALS AND METHODS}

The stages in constructing ALCHA can be explained as follows:

Preparing hardware component: The general components used to construct ALCHA are DT sense current sensor Intel Galileo microprocessor, SD card for stored data, Firebase and smartphone that compatible with Android systems. The prototype of ALCHA can be seen in Fig. 1.

Technics of signal measurement and signal conversion: The general process of signal measurement and signal conversion are shown in Fig. 2 and 3.

From Fig. 2 it can be seen that there are seven main parts of the ALCHA prototype design. For detecting harmonics until harmonics 9th $(450 \mathrm{~Hz})$, ALCHA at least required data sampling of 3000 data per second stored in memory. The data packets per second are then process in microprocessor by using DFT to transform data in time domain to frequency domain. The equation used for processing data transformation from time domain to frequency domain using DFT as in Eq. 1 and 2:

$$
X(k)=\sum_{j=1}^{N} x(j)\left(N^{(j-1)(k-1)}\right.
$$

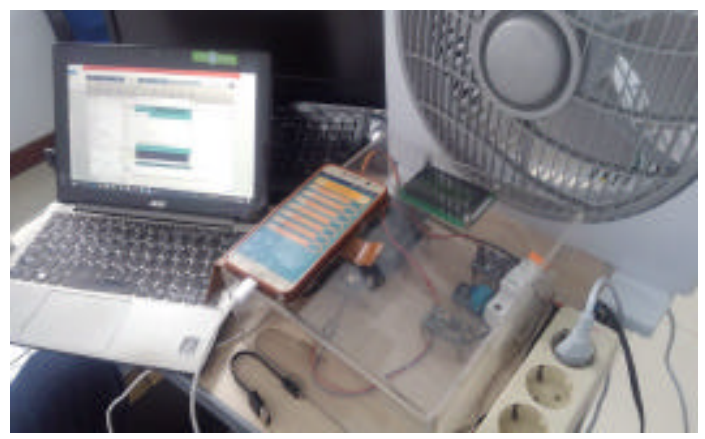

Fig. 1: Prototype of ALCHA

$$
x(j)=\left(\frac{1}{N}\right) \sum_{j=1}^{N} x(k)\left(N^{(j-1)(k-1)}\right.
$$

with, $\mathrm{N}=$ Number of sampling data $(\mathrm{N}=\mathrm{e}-2(\mathrm{i}) / \mathrm{N}$. The transformation process from time domain to frequency domain (Baird and Arrilaga, 1980) is employing C++ as software.

Online monitoring: For online monitoring purposes, the data in frequency domain send to Wi-Fi module. It should

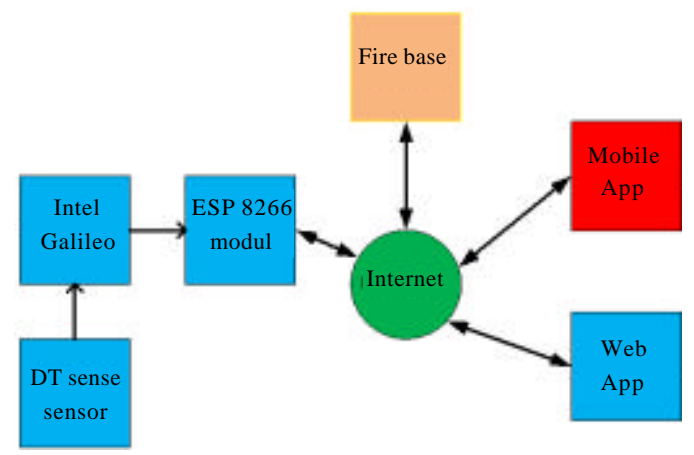

Fig. 2: General process of signal measurement and signal conversion

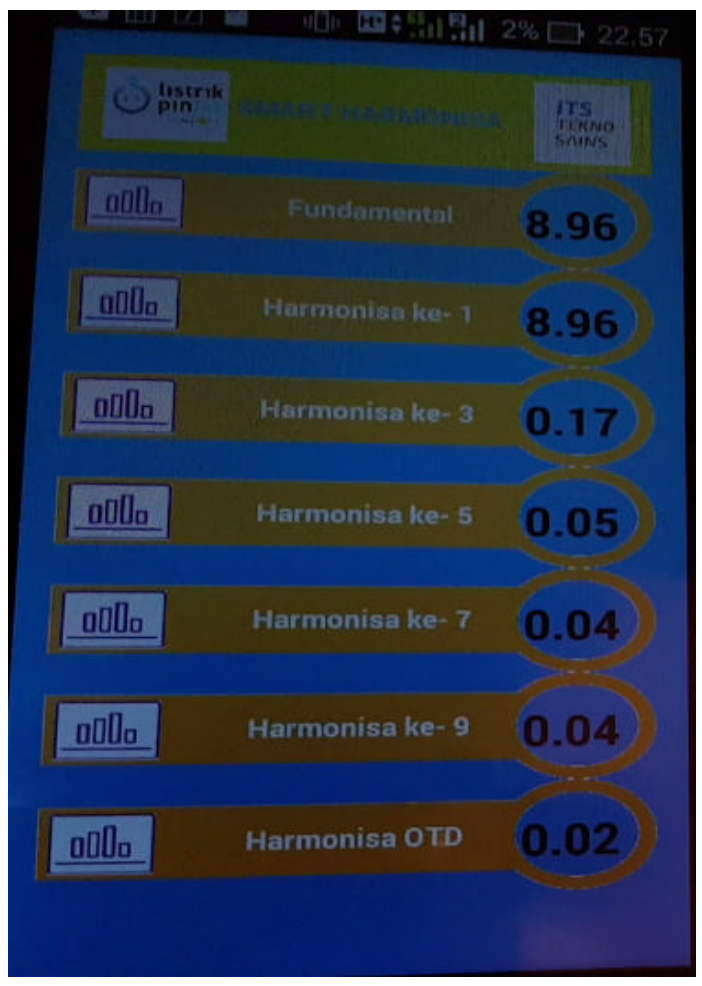

Fig. 3: Design of ALCHA Android view 
be noted that the Wi-Fi module must be compatible with Intel Galileo and Firebase. Wi-Fi sends data to a data base system (firebase), so that, data can be accessed using both Android and the web. The design of Android layout can be seen in Fig. 3 .

\section{RESULTS AND DISCUSSION}

Experiment and data analysis: In this study, ALCHA performance verification is carried out in three experimental cases in each case an electrical signal from the power system (Indonesian Electric Company/PLN) will be tested as well as a signal from micro grid systems:

The first case: Experiment conduct by using light bulb as load and it connected to the power source from PLN and comparing to power source from microgrid.

The second case: Experiment conduct by using cellphone charging process as load and it connected to the power source from PLN and comparing to power source from microgrid.

The third case: Experiment conduct by using cellphone charging process and fan that are operated simultaneously as load and they connected to the power source from PLN and comparing to power source from microgrid.

The observations of three cases mention earlier are focused on current harmonics on range frequency $50-450 \mathrm{~Hz}$ (Fundamental to Harmonics 9th) with $220 \mathrm{~V}$ Voltage level.

Case 1: The experiment in this case aims to identify the level of harmonics in the power source light bulb as load and it connected to the power source from PLN and comparing to power source from microgrid. The results of the experiment can be seen in Fig. 4 and 5.

Figure 4 shown the signal of power source from PLN has frequency $50 \mathrm{~Hz}$ and there is no harmonics distortion detected in this experiment.

Figure 5 shown the signal of power source resulting from micro grid with the light bulb load. From the figure can be seen that there are harmonics distortion, i.e. The $3 r d$ tharmonics, the 5 th harmonics and the 7 th harmonics. Total Harmonic Distortion (THD) of the signal is $32 \%$. According to IEEE-519 standard, the signal is alreday out of the limit.

Case 2: Experiments in this case aim to identify the level of harmonics caused by cellphone charging. Cellphone

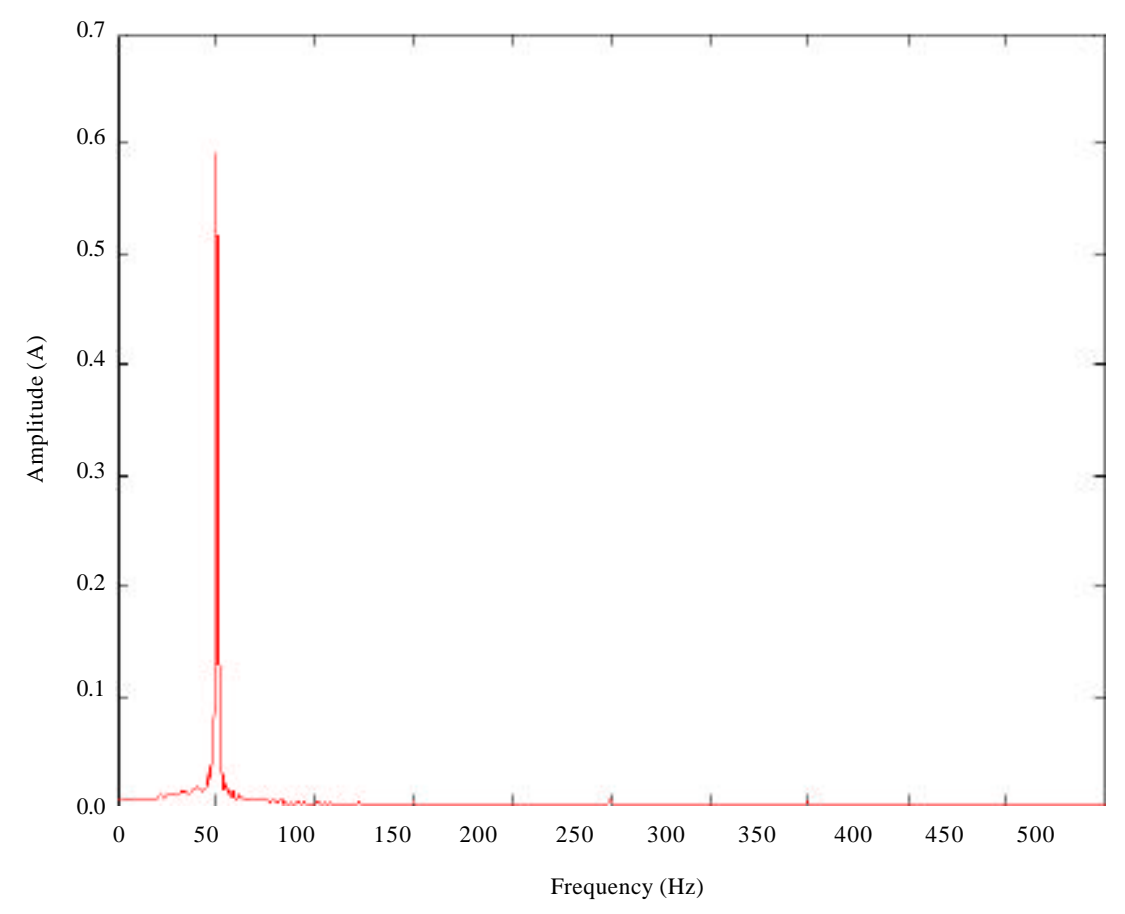

Fig. 4: The signal of power source from PLN with light bulb as load (Hormonic spectrum) 
J. Eng. Applied Sci., 14 (21): 7988-7995, 2019

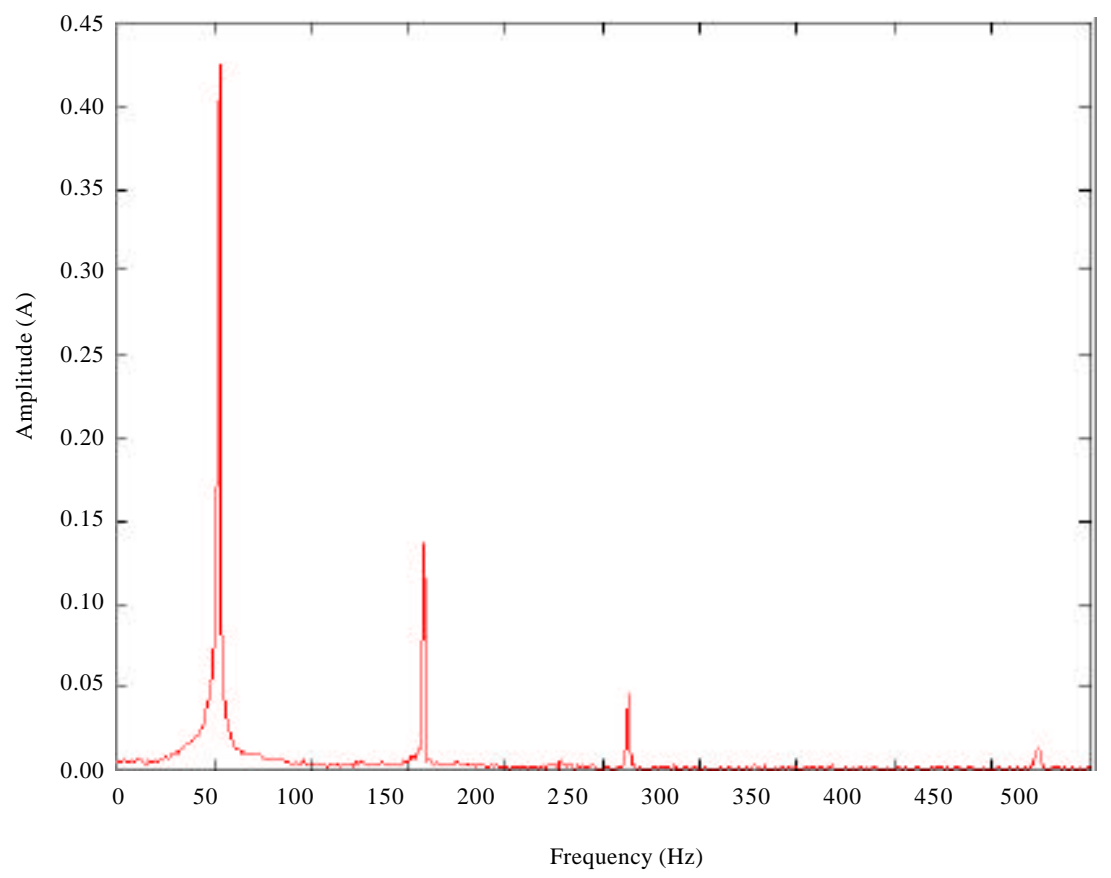

Fig. 5: The signal of power source from microgrid with light bulb as load (Hormonic spectrum)

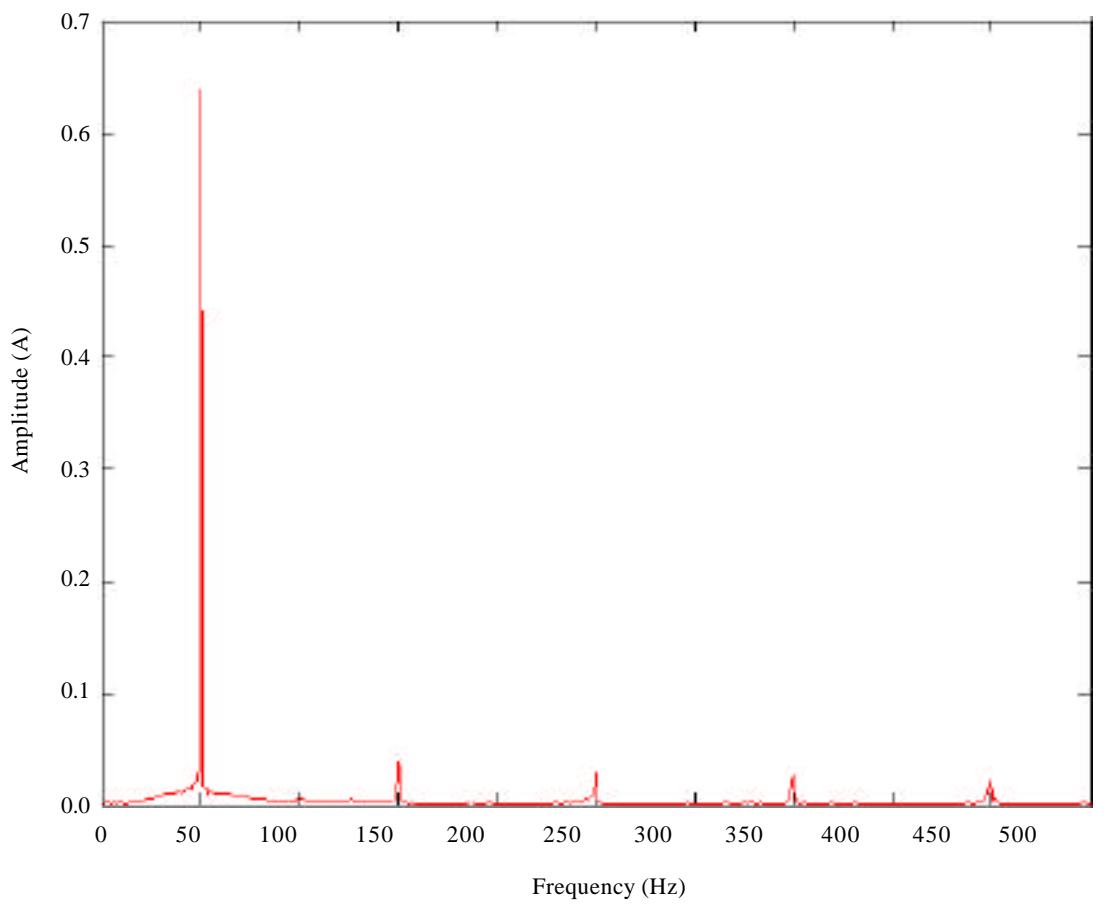

Fig. 6: The signal of power source from PLN with charging cellphone as load (Hormonic spectrum)

charging process is the most frequent activity in the modern life. The results of this experiment can be seen in Fig. 6 and 7.
Figure 6 shown the signal of cellphone charging process measured by ALCHA with power source from PLN. From the figure can be seen that there is harmonic 


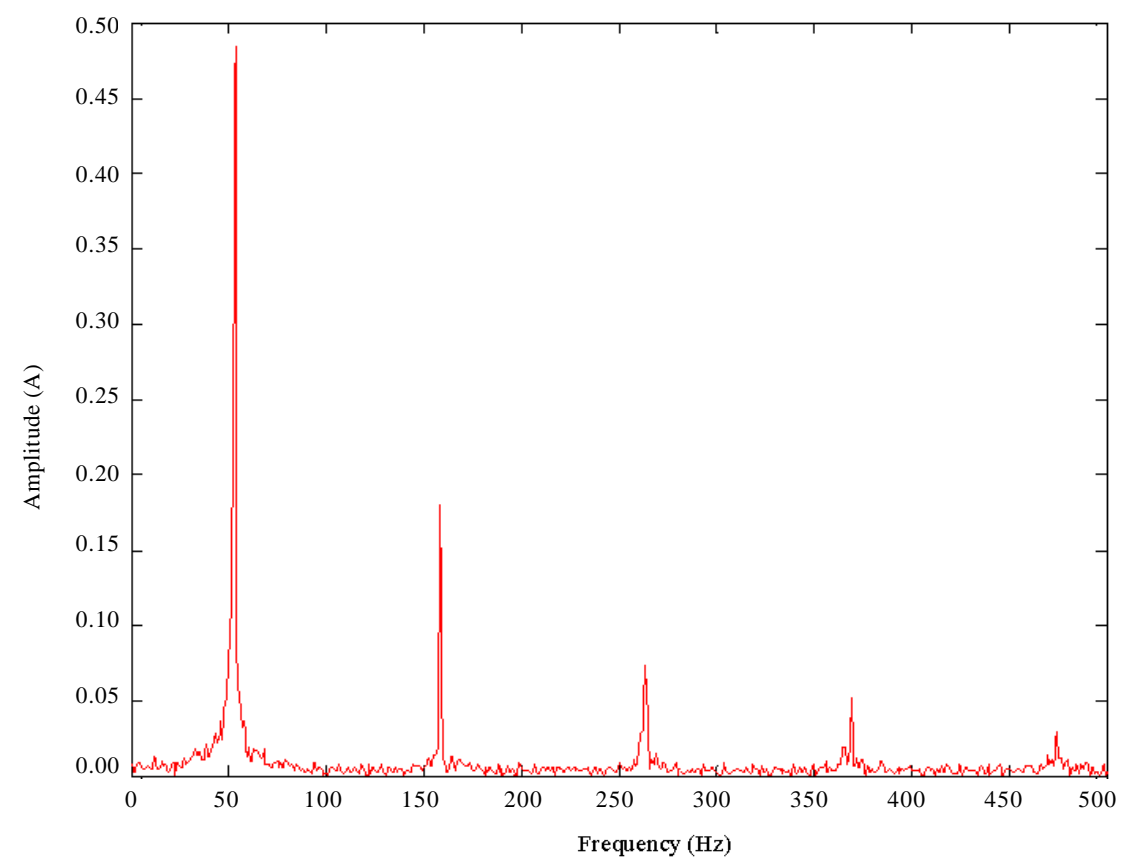

Fig. 7: The signal of power source from car's with charging cellphone as load (Hormonic spectrum)

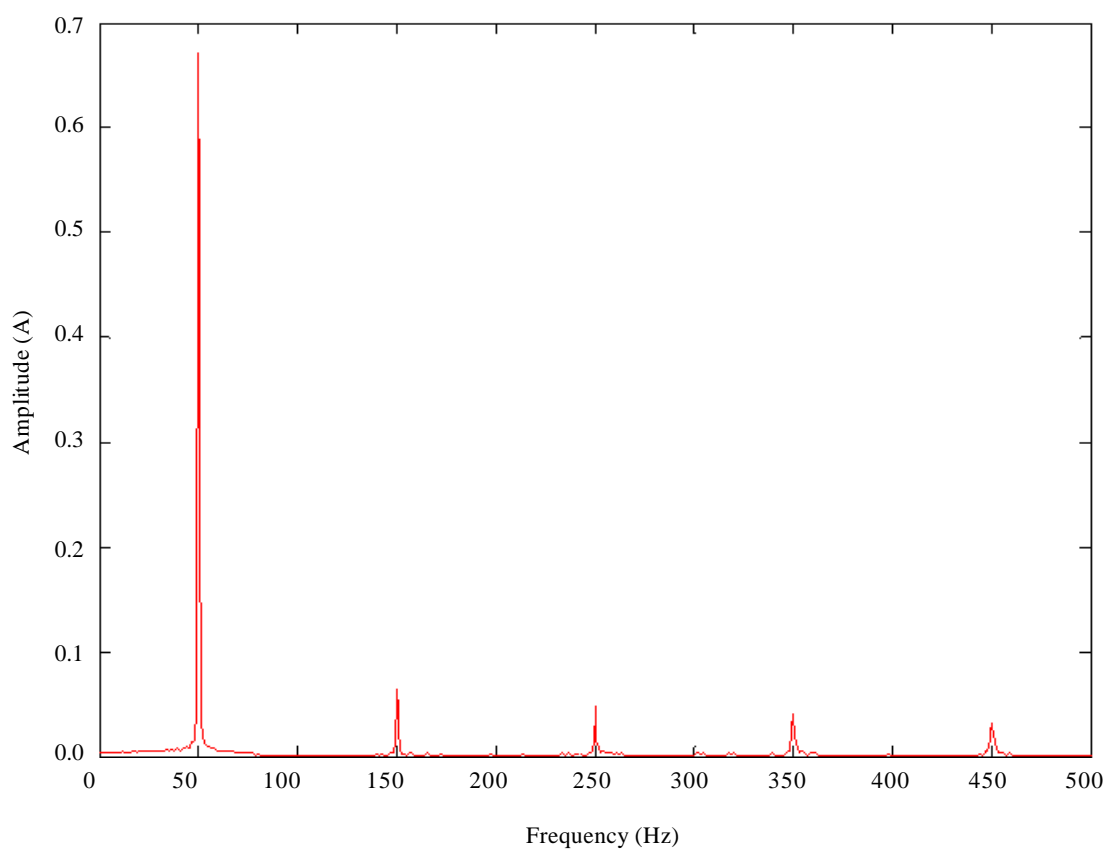

Fig. 8: The signal of power source from PLN with charging cellphone as load was operated simultaneusly with pure resistor (Hormonic spectrum)

distortion in the signal, i.e., harmonics 3rd., 5th, 7th and 9th. The Total Harmonic Distortion (THD) is 3.99\%. According to the IEEE-519 standard this signal is categories as good signal.
Figure 7 and 8 shown the signal of cellphone charging process measured by ALCHA with power source from micro grid. From the figure can be seen that there is harmonic distortion in the signal, i.e., harmonics 


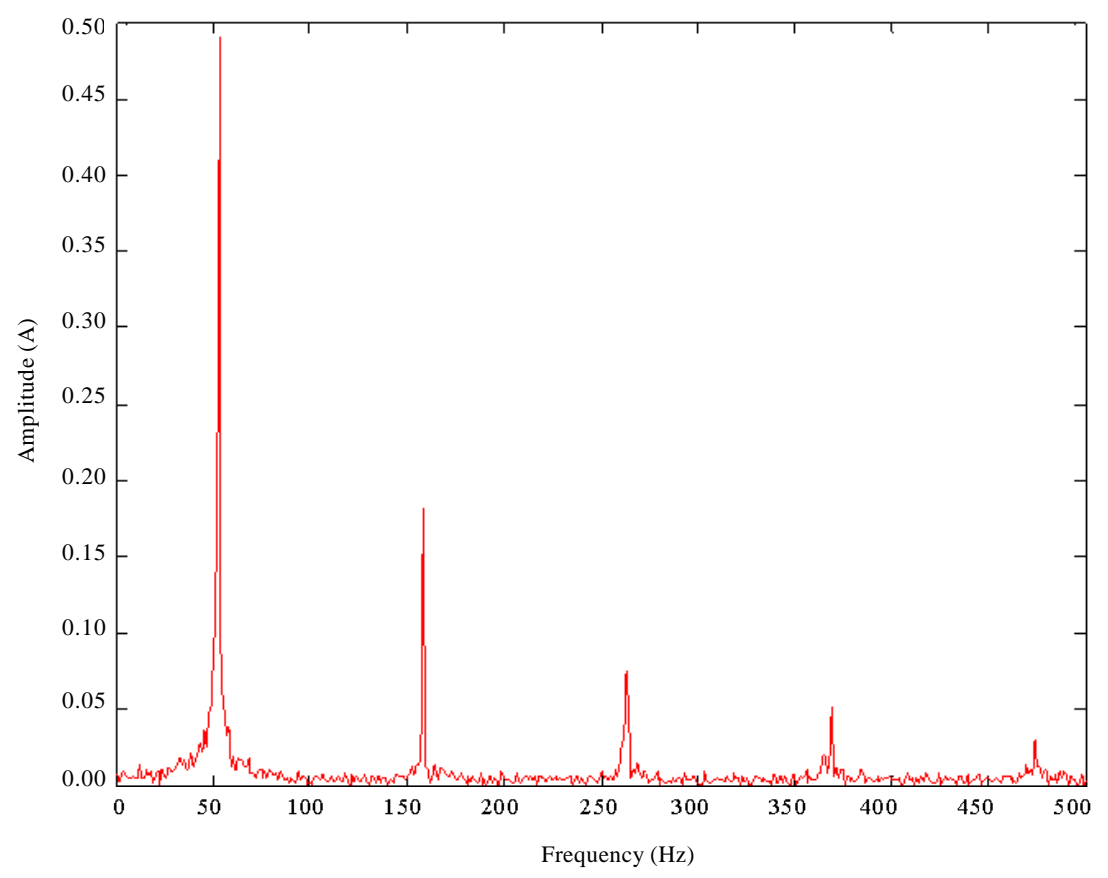

Fig. 9: The signal of power source from car's inverter power source with charging cellphone as load (Hormonic spectrum)

3rd., 5th, 7th and 9th. The Total Harmonic Distortion (THD) is $37 \%$. According to the IEEE-519 standard this signal is also categories as over the limit.

Case 3: This third case is aimed to measure harmonic distortion of charging process of cellphone was conducted simultaneously with fan using power source from PLN and comparing to power source from microgrid. The results of this experiment can be seen in Fig. 8 and 9.

Figure 8 shown the signal of cellphone charging process operated simultaneously with fan measured by ALCHA with power source from PLN. From the figure can be seen that there is harmonic, i.e., harmonics 3rd., 5th, 7th and 9th. The Total Harmonic Distortion (THD) is $8 \%$. According to the IEEE-519 standard, this signal is also categories as over the limit.

Figure 9 shown the signal of cellphone charging process operated simultaneously with fan measured by ALCHA with power source from microgrid. From the figure can be seen that there is harmonic distortion in the signal, i.e., harmonics 3rd., 5th, 7th and 9th. And using (Goh et al., 2017) the Total Harmonic Distortion (THD) is $39 \%$. According to the IEEE-519 standard, this signal is also categories as over the limit.

From the three cases experiments were conducted, all of the result also verify with harmonic analyzer laboratorium scale (Goh et al., 2017). And the average result of OHMC'sI and Harmonics Analyzer standard industri is around $1.42 \%$.

\section{CONCLUSION}

Based experimental results, it can be concluded that ALCHA has good performance in monitoring harmonics either harmonics resulted by power system or microgrid systems. Compared with harmonic analyzer laboratory scale, ALCHA has a standard deviation of $1.42 \%$ indicating that ALCHA has a great chance of being mass produced. And from the experiment results also shown than the power quality resulted by PLN is fulfill the requirement of IEEE-519 standard.

\section{REFERENCES}

Adhitya, R.Y., M.A. Ramadhan, S. Kautsar, N. Rinanto and S.T. Sarena et al., 2016. Comparison methods of fuzzy logic control and feed forward neural network in automatic operating temperature and humidity control system (Oyster Mushroom Farm House) using microcontroller. Proceedings of the International Symposium on Electronics and Smart Devices (ISESD), November 29-30, 2016, IEEE, Bandung, Indonesia, ISBN:978-1-5090-3841-1, pp: 168-173. 
Agarwal, R. and S. Singh, 2014. Harmonic mitigation in voltage source converters based HVDC system using 12-pulse AC-DC converters. Proceedings of the Annual International Conference on India Conference(INDICON), December 11-13, 2014, IEEE, Pune, India, ISBN:978-1-4799-5362-2, pp: 1-6.

Baird, J.F. and J. Arrilaga, 1980. Harmonic reduction in dc-ripple reinjection. IEEE Proc. Gener. Trans. Distrib., 127: 294-303.

Chang, H.H., K.L. Lian, Y.C. Su and W.J. Lee, 2014. Power-spectrum-based wavelet transform for nonintrusive demand monitoring and load identification. IEEE. Trans. Ind. Appl., 50: 2081-2089.

Cho, Y.W., J.M. Kwon and B.H. Kwon, 2014. Single power-conversion AC-DC converter with high power factor and high efficiency. IEEE. Trans. Power Electron., 29: 4797-4806.

Cottinet, P.J., M . Lallart, D. Guyomar, B. Guiffard and L. Lebrun et al., 2011. Analysis of AC-DC conversion for energy harvesting using an electrostrictive polymer $\mathrm{P}$ (VDF-TrFE-CFE). IEEE. Trans. Ultrason. Ferroelectr. Freq. Control, 58: $30-42$.

Duckett, E.J., 1962. DC-AC power conversion by semiconductor converters. IRE. Trans. Ind. Electron., 9: 48-55.

Goh, Z.P., M.A.M. Radzi, H. Hizam and N.I.A. Wahab, 2017. Investigation of severity of voltage flicker caused by second harmonic. IET. Sci. Meas. Technol., 11: 363-370.

Hostetter, G., 1980. Recursive discrete Fourier transformation. IEEE. Trans. Acoust. Speech Signal Process., 28: 184-190.

Isozaki, J., K . Suzuki, W. Kitagawa and T. Takeshita, 2016. PWM strategies with duality between current and voltage source $\mathrm{AC} / \mathrm{DC}$ converters for suppressing $\mathrm{AC}$ harmonics or $\mathrm{DC}$ ripples. Proceedings of the International Conference on Energy Conversion Congress and Exposition (ECCE), September 18-22, 2016, IEEE, Milwaukee, WI, USA, ISBN:978-1-5090-0738-7, pp: 1-8.

Jaipradidtham, C. and P. Inban, 2009. The harmonic impedances and voltage source transients model of 12 pulse AC-DC converters for harmonic flow analysis using discrete wavelet transform. Proceedings of the International Conference on TENCON 2009-2009 IEEE Region 10 Conference, January 23-26, 2009, IEEE, Singapore, Singapore, ISBN:978-1-4244-4546-2, pp: 1-4.

Lian, KL. and M. Syaiin, 2014. Steady-state solutions of a voltage source converter with dq-frame controllers by means of the time-domain method. IEEJ. Trans. Electr. Electron. Eng., 9: 165-175.
Mohebbi, M., M.L. McIntyre and J. Latham, 2015. Energy efficient DC to $\mathrm{AC}$ power conversion using advanced controllers and novel voltage trajectories. Proceedings of the 16th Workshop on Control and Modeling for Power Electronics (COMPEL), July 12-15, 2015, IEEE, Vancouver, BC, Canada, ISBN:978-1-4673-6846-9, pp: 1-8.

Putra, R.Y., S. Kautsar, R.Y. Adhitya, M. Syaiin and N. Rinanto et al., 2016. Neural network implementation for invers kinematic model of arm drawing robot. Proceedings of the International Symposium on Electronics and Smart Devices (ISESD), November 29-30, 2016, IEEE, Bandung, Indonesia, ISBN:978-1-5090-3841-1, pp: 153-157.

Rinanto, N., R.Y. Adhitya, S.T. Sarena, S. Kautsar and I. Munadhif et al., 2016. Rotor bars fault detection by DFT spectral analysis and extreme learning machine. Proceedings of the International Symposium on Electronics and Smart Devices (ISESD), November 29-30, 2016, IEEE, Bandung, Indonesia, ISBN:978-1-5090-3841-1, pp: 103-10.1109/ISESD.2016.7886701.

Shi, R., S. Semsar and P.W. Lehn, 2017. Constant current fast charging of electric vehicles via a DC grid using a dual-inverter drive. IEEE. Trans. Ind. Electron., 64: 6940-6949.

Syai'in, M., A. Soeprijanto and I. Negara, 2012. Incremental particle swarm optimizer with local search for optimal power flow subjected to digital GCC based on neural network. Intl. J. Digital Content Technol. Appl., 6: 242-252.

Syai' in, M., M.F. Adiatmoko, I. Rachman, L. Subiyanto and K. Hutoro et al., 2014. Smart-meter based on current transient signal signature and constructive backpropagation method. Proceedings of the 2014 1st International Conference on Information Technology, Computer and Electrical Engineering (ICITACEE), November 8, 2014, IEEE, Semarang, Indonesia, ISBN:978-1-4799-6431-4, pp: 144-149.

Syaiin, M. and A. Soeprijanto, 2012. Regular paper combination of generator capability curve constraint and statistic-fuzzy load clustering algorithm to improve NN-OPF performance. J. Electr. Syst., 8: 198-208.

Syaiin, M., K.L. Lian and A. Soeprijanto, 2013c. Digital generator capability curve for improving optimal power flow based on IPSO. J. Digital Eng., 8: 912-918.

Syaiin, M., K.L. Lian and T. H. Chen, 2013b. Improved robustness of sequential three phase power flow using homotopic method. Intl. Rev. Electr. Eng., 8: 346-353. 
Syaiin, M., K.L. Lian, N.C. Yang and T.H. Chen, 2012. A distribution power flow using particle swarm optimization. Proceedings of the International Conference on IEEE Power and Energy Society General Meeting, July 22-26, 2012, IEEE, San Diego, USA, ISBN:978-1-4673-2727-5, pp: 1-7.

Syaiin, M., O. Penangsang and A. Soeprijanto, 2013a. Real-time unbalanced load flow development using direct-ZBR method and modified Lambda iteration for on-line monitoring and control. Proceedings of the 22nd International Conference and Exhibition on Electricity Distribution (CIRED 2013), June 10-13, 2013, IEEE, Stockholm, Sweden, ISBN:978-1-84919-732-8, pp: 1-1
Syai' in, M. and A. Soeprijanto, 2010. Neural network optimal power flow (NN-OPF) based on IPSO with developed load cluster method. World Acad. Sci. Eng. Technol., 72: 48-53.

Zhang, D., F. Wang, R. Burgos, R. Lai, T. Thacker and D. Boroyevich, 2008. Interleaving impact on harmonic current in DC and $\mathrm{AC}$ passive components of paralleled three-phase voltage-source converters. Proceedings of the International Conference on 23th Annual IEEE Applied Power Electronics Conference and Exposition, February 24-28, 2008, IEEE, Austin, TX, USA., ISBN:978-1-4244-1873-2, pp: 219-225 